\title{
Freedom to Choose One's Own Health Care
}

\author{
Ivo Telec ${ }^{1}$
}

Faculty of Law, Palacky University Olomouc, Czech Republic

ivo.telec@upol.cz.

TELEC, Ivo. Freedom to Choose One's Own Health Care. International and Comparative Law Review, 2017, vol. 17, no. 2, pp. 143-155. DOI 10.2478/iclr2018-0020.

\begin{abstract}
Summary: Taking care of one's own health belongs to the diversity of the culture and religion. This concerns not only the conventional medical services on the market but also the traditional medicine. When selecting one's own health care, a significant role is played not only by one's personal experience but also by one's worldview or religious beliefs. The methods of health care differ in the degree of reliability of evidence. Various forms of evidence are established by the law of medicinal drugs. Certain restrictions on health care concern livestock in organic farming. In these cases, the law system favors the homeopathic products before the allopathic ones. Freedom to choose one's own health care also concerns natural healing. The Czech law recognizes its practitioners as experts in the private law sense being obliged to act with due care of experts. Natural healing is sometimes associated with religious beliefs. In the Czech Republic there is a constitutional ban on being bound by an exclusive ideology or religion. From the perspective of human rights and biomedicine there is preference of the interests and welfare of human beings to the interests of society or science.
\end{abstract}

Keywords: freedom, health care, natural healing, professional duty of care, religion.

\section{Introduction}

Human health is among the important and legally protected values. It is associated with the uniqueness of each person and legally recognized natural rights of people. Health of each of us is different and changeable. It is often linked to the overall wellbeing and lifestyle and eating habits. People also tend to have different constitutions so there are multiple ways to take care of their own health and to make use of differently oriented services on the market. A certain health care is directed mainly to biological processes in the human body. Other approaches may be psychosomatic, psychological or even spiritual ones. Such approaches tend to focus on the inner change of the patient's condition and his overall approach to life. Methods of health care vary in relation to the degree of one's own activities, not mentioning the extent of one's own financial payments or payments from the public health insurance system.

1 Prof. JUDr. Ivo Telec, CSc., Head of the Department of Private Law and Civil Procedure, Faculty of Law, Palacky University in Olomouc, Czech Republic; e-mail ivo.telec@upol.cz. 
The attitudes of health workers, healers, or clergymen to human health tend to be different. There is a question of what a human being is and what his/her essence is. Different answers may be given by an atheist, a Hindu, or perhaps a neo-Marxist, a Catholic or a supporter of the New Age movement. Doctors and psychologists themselves differ in their opinions. Some of them have been pointing out for years that the biomedical and engineering model of Western medicine, despite the continuous technical progress and good results, has been exhausted in its humanistic essence that was biologically narrowed to matter only. Yet we marvel at an incredibly rapid evolution of technology and medical devices which brings considerable hopes. The above mentioned biomedicalengineering model, however, has its critics, too. ${ }^{2}$

The title of specialized doctor once suggested that such a person further educated himself in his field to keep pace with the progress of medical science and art of medicine. ${ }^{3}$ For example, dentistry, legally speaking, used to be a field of science and art of medicine. ${ }^{4}$ But art did not mean artistic beauty or artistic creation but an art or a skill to heal. Healing still primarily means trying to heal the patient, including an effort to determine the causes of a disease in order to prevent it. The traditional concept of the art of medicine was abandoned in Czechoslovakia in 1950. The medical profession started to be associated with „Construction of socialism“ by the Communists. After 1989, there was no legal return to art of medicine. Conversely, the 2011 Health Services Act, because of some deputies' amendments to the governmental bill, emphasized the „rules of science" as such. In general, there was no room left for art and medicine and clinical experience.

\section{Diversity of health care}

Health care is as diverse as culture or religion. We may come across spiritual therapy, for example, in the form of pastoral medicine, including clinical pastoral care. In addition, there is a variety of natural healing approaches, including what is called traditional medicine, whether the Western or Eastern ones, such as from India or Japan. In addition, the market offers medical services in the form of conventional medicine of the Western scientific style. The latter tends to be irreplaceable especially in the emergency medical service, in injuries, etc.

2 E.g. ILLICH, I.: Limity medicíny. Nemesis medicíny - zaprodané zdraví. Brno, Emitos 2012. The English original (Limits to Medicine. Nemesis of Medicine, the Expropriation of Health) was published in 1976. The author was a philosopher, not a doctor. In the Czech philosophical literature cf. works by KOMÁREK; see KOMÁREK, S.: Tělo, duše a jejich spasení aneb Kapitoly of moci, nemoci a psychosomatice (The body, soul and salvation, or Chapters of power, illness and psychosomatics). Praha, Academia 2015.

$3 \$ 1$, Para. 1, Sub-Para. c) Gov. Reg. No. 39/1932 Coll., on the use of the title of specialized doctor, canceled on January 1, 1951.

$4 \$ 1$, Para. 1, the Act. No. 303/1920 Coll., on dentistry and dental technology, canceled on 1 January 1951. 
Health services also include those of psychosomatics. The professional capacity of a psychosomatic was not, however, legally established until $2013 .{ }^{5}$ In contrast to some other countries, this happened with many years of delay to the detriment of Czech patients.

What is certain is that sometimes there is no other way than penetrating deeper into the inner world of a sick person. In such a case, the ordinary imaging or radiating medical technology usually are not sufficient. The human soul, emotions and inner spiritual experience tend to be impenetrable by the medical equipment.

People are free. Some of them prefer more traditional herbal medicines with therapeutic indication, medicinal teas and blends, some of which containing very efficient ingredients, or food supplements with physiological effects. Others may be impressed, depending on their nature, by drugs based on synthetic chemicals. Both approaches have their advantages, or, conversely, disadvantages associated with danger, for example in the form of undesirable side effects. It undoubtedly requires great skills to judge when it is suitable to use this or that for particular individuals with their unique health constitutions. If a specific medical procedure suits well the majority of people, it may not suit the minority, and vice versa, not to mention particular human beings. Just consider the state of pregnancy or lactation, when the use of a number of drugs is excluded because of their potentially hazardous effects. Various restrictions also apply when someone's body is resistant to antibiotics or when someone is allergic to certain substances. The impact of radiation has to be taken into account, too. Then alternative natural methods may come in handy.

Treatment of minor illnesses usually does not require a prescription of medicines or medical supervision. Self-medication or home care, including self-medication accompanied with a good public health education, have their role, too. Nothing is required from the public health insurance so its payments may be targeted to where they are really needed.

When selecting one's own health an important role is played not only by personal experience but also by someone's worldview, religion or belief. For example, in a medically diagnosed condition of obsession, ${ }^{6}$ an atheist and a materialist, after exhausting other treatments, may agree with a psychosurgical intervention in the brain. A materialist does not recognize the existence of his soul, let alone someone elses. A Roman Catholic, in turn, may agree with exorcising the evil spirit. In the Czech Republic, exorcism has been practiced by the Roman Catholic Church depending on circumstances after the failure of health services provided according to the "rules of science." Other people may try to

5 However, according to some medical opinions it should not be a special expertise but a common approach of every doctor.

6 See Para. F 44.3, International Classification of Diseases and Related Health Problems (ICD-10), report No. 495/2003 Coll., as amended. 
find a healer. Ideological differences and their manifestations tend to be obvious. Some people advocate the materialistic scientific worldview in the form scientific naturalism being at the same time, as the Roman Catholics, followers of exorcising the evil spirit. Other people may find this rather odd.

The risk of choosing a bad health care is up to everyone alone. This concerns mainly the danger of delaying the start of a truly effective treatment in particular cases. It may happen that a misdiagnosis or incorrect treatment have been the result of actions by a third party resulting in expenditures on health services covered by the public health insurance, which would not occur otherwise. In such a case, the health insurance company has a legal right to reimbursement of health services costs covered by the public health insurance, if those services were incurred as a result of an unlawful conduct against the insured person. It is irrelevant which third party caused the public expenditure by his/her wrong actions, whether a doctor, a healer, a clergyman or anyone else. Healthcare providers have a duty to notify, in the case of a "reasonable suspicion," that the damage to the patient's health was caused by the acts of another person. Notification obligation applies to the relevant government authorities, too.

Another issue is a possible condition of lack of evidence. This condition may concern all disputes over neglected health care, i.e. defective performance of services on the market. The State generally tries to prevent that by requiring mandatory medical records for medical professions and imposing recording duty for healers. Only clergymen are left aside. However, not only the state of evidence is involved but also the judgment about causation, or mere correlation. These legal issues concern any harm to the mental or physical health, regardless of their origin. Tort law has its own conception of causality assessment, including weighing the possible concurrence of probabilities.

\section{Reliability and types of evidence, and welfare of the patient}

Various offers with alleged effects on health include products or practices of both conventional scientific and non-scientific nature. Hence different kinds of evidence for effectiveness or safety. The degree of evidence reliability is not the same, either. The international scientific research on human health takes the diversity of practice into account. There is not only quantitative research but also the qualitative one. Both of them are methodologically different, while making use of generally accepted scientific procedures.

Empirical evidence may be of various kinds. Besides randomized experiments of the double blind experiment type there are observations, long-term common experience with positive symptoms in patients, i.e. tradition, casuistry, and others. What may matter is also a well-established tradition of a certain substance or practice. Misunderstandings that sometimes occur are methodological in nature, including the question what reference framework we are in. 
For example, as the Indian Ayurveda or the European or Indian homeopathy have constitutional types based on their own theories, we, when following these theories, may hardly achieve the same or any other effect with the same product in anyone according to a random sample. In allopathic medicine it tends to be opposite.

There is a well-known Haynes pyramid of scientific evidence according to the degree of their scientifically probative value. The conventional scientific evidence-based medicine is established on the assessment of the best evidence with clinical experience. But the problem is usually somewhere else. For example, the traditional medical knowledge of Amazonian Indians or Siberian shamans is also based on evidence. However, in objective terms of the positivist theory of science such evidence may not be considered reliable. In the Haynes pyramid it would be very low. But if something is not proven, say, by a statistical meta-analysis of data, it need not necessarily mean that the phenomenon does not exist or that a particular practice has never been effective. Such a conclusion would be nonscientific. In addition, the spiritual world cannot certainly be subject to examination by natural sciences. They can only assess its external manifestations, if there are any. A sick person in his unique life situation of suffering actually does not care of a meta-analysis of data of any kind. The impact factor of the journal in which the results were published did not heal anyone, either. A scientifically correct conclusion should therefore be that by a specific procedure, in a certain framework of reference, efficacy has not been verified. Nothing more, nothing less. Anything else would be more of an ideology. It is our freedom, if and when we undergo the potential risk of diagnosis or treatment based on conventionally weak evidence. Sometimes, however, the mere hope of healing can help.

Ways of proving the efficacy and safety of medicinal products are provided for by the law of medicinal products. There are a number of such legal manners. They vary in the case of allopathic and homeopathic products, or traditional herbal medicinal products. The European Pharmacopoeia and the Czech Pharmacopoeia have diverse contents according to their different starting points.

However, the sick person is only interested in a chance of being healed, not in methodological disputes or the degree of reliability of some evidence. $\mathrm{He} /$ she has absolutely no interest in ideological frictions or disputes among philosophical and scientific schools, or even power squabbles and connections on the market.

The research question is whether there is causality or only correlation between a particular way of effecting health and positive symptoms in a patient. These questions have to be taken into account also in animals where autosuggestion may be excluded quite certainly. A captivating impact on an animal by a breeder (suggestion) putting in a cow the wish of recovery can be different than in the case of suggestion to humans, if it is significant at all. Neither one can 
rule out various hidden causes defying a science discovery. A scientific solution of such questions is sometimes so loaded with different philosophical theories, or even prejudices, that the conclusions may not be scientifically accepted at all. Therefore, a substantial part of research avoids these things. Avoiding problems has never solved anything, though.

Although health services do not belong to the scientific development and a member of the medical profession is not a scientist, health services in the Czech Republic are supposed to be provided according to „rules of science." However, patients do not examine their general practitioners if they know „rules of science“, scientific terms, „science of science“, or the latest intellectual arguments between the world's philosophers of science. Medical professions are entirely practical regardless of the stability or volatility of medical doctrines, scientific paradigms or their ideological bases. The patient expects from the doctor or clinical psychologist something completely different than gaining new scientific knowledge about the psyche or body, which would otherwise be the purpose of "rules of science" as a kind creation.

A scientific interest in the highest possible level of reliability of evidence of efficacy and safety of certain substances, medical aids or practices is legitimate, especially in the field of man-made chemical drugs. On the other hand, the scientific interest (and the doctrine based on it) is subordinated by international law to a higher value which is the welfare of the patient and his/her interest explicitly having preference to the interests of science or health services as a component of society. This follows from the Convention on Human Rights and Biomedicine. The patient's interest is to recover, or at least to be alleviated from his/her suffering, and to maintain a certain quality of life, both physical and mental one, regardless of the ideology or worldview or profession of the person who tries to help him/her. Therefore any way of effecting one's health which is led by a sincere effort to help is justifiable, if it is not to that person's detriment. Since the Czech health care system is hugely, one could say even excessively, legally restricted, there is an open wide space for other services on the market which are governed by their own rules; cf. $\$ 2643$ Para. 1, Civil Code. Freedom of choosing one's own health care cannot be tied to any exclusive scientific worldview in any form, nor with scientific naturalism. Neither it can be legalistically narrowed to the fields of health care set forth by the State nor is it possible to wait for some changes made by ministry decrees. Illness never waits.

In spite of that, the freedom of choosing one's health care is legally restricted in the Czech Republic.

\section{Bees}

The restriction applies to the health of the livestock kept on organic farms. In 2000, a legal obligation was imposed on ecological entrepreneurs. Accord- 
ing to the results of a veterinary examination they had to use primarily natural and homeopathic products when treating the diseased animals. ${ }^{7}$ In the following year, this was were established for the Central European honeybee ecotype, too. ${ }^{8}$ Since joining the EU in 2004, similar provisions of the European law have been applied in the Czech Republic, too. The European Economic Community resolved these things in 1992. The purpose is quality and protection of animal products from organic farms.

Homeopathic products, though, apparently do not have an active ingredient in the conventional material sense. According to the scientific naturalism, there are no subtle-material or intangible information, so such products are considered ineffective, perhaps except for a placebo effects. But how does the effect of placebo work in bees?

Placebo may work in humans if the recipient of the substance does not know that the substance is ineffective right for him/her. The patient lives in a mistake that he/she uses an effective product but it is not actually the case. But how does placebo work with homeopathic products where from the beginning one knows that it is only a placebo and so the principle of placebo, or "mechanism of effect" of an ineffective substances is not followed. This may not even concern human homeopathic products, which are issued (properly "sold") only on prescription. If one buys something, knowing in advance that it is ineffective, then the placebo effect cannot come as it is based just on the opposite, i.e. on not knowing the inefficiency of a certain product.

Another question is which of the legal reasons for "providing" certain human homeopathic products only on the basis of a medical prescription way officially considered if it should be an ineffective substance; cf. $\$ 39$, Act. No. 378/2007 Coll., on pharmaceuticals.

\subsection{More questions than answers.}

It happens that the answer is already predetermined by our worldview. Someone could even see a "drug conspiracy" of the Council of Europe and the European Union in such an issue. Perhaps we will be surprised in the future by the "information medicine" as it is sometimes called. Sick people are not interested in research on the mechanism of effects of a certain medical product but only in the fact whether "it will work or not". An atheist and a secular humanist does not heed warnings from Roman Catholic circles against hidden spiritual forces of homeopathy. Some deny the existence of such forces, others warn against their effects. Other people do not care, and may sometimes use homeopathic remedies. Others had to use them in some animals. The society is truly diverse.

$7 \$ 14$ Para 1, Sub-Para h), the Act. No. 242/2000 Coll., on organic farming.

$8 \$ 23$ Para 5, Reg. No. 53/2001 Coll., which implements the Act No. 242/2000 Coll., on organic farming and on amendment of the Act No. 368/1992 Coll., on administrative fees, as amended. 
A person believing in materialism may say, "What cannot be measured does not exist, even when I can see it. It is a self-deception." From his/her point of view he/she is certainly right. Someone else is looking in life for "invisible" phenomena of subtle-material or spiritual nature irrespective of the sensitivity of the medical equipment. There are many interpretations, ranging from revelation, perhaps in the form of "source information" on how to live unharmed in the world, to various philosophical or medical schools of the West or the East. According to many, it is better to be a person healed unscientifically than a chronically ill one in whom scientific processes were applied. Believing in something different or different beliefs in the general sense of the word is an undeniable fact which is quite typical of the civic society.

\section{Natural healing}

Natural medicine is largely based on a tradition combined with generally good experience. It is traditional knowledge which includes traditional medicine, and it has long been politically supported by the World Health Organization. The aim is to include traditional medicine into the national health system of the member countries. It does not matter whether it is a developing country or an economically and technically advanced one. But the fact is that if something is traditional it does not mean that it is necessarily good. Therefore, we must put emphasis on a good tradition, confirmed by at least a long-term observation of multiple phenomena as traditional facts may sometimes be very stupid, too.

Last time the Czech Government took note of the existence of healing by its resolutions from 2011 and 2009, when approving the drafts of the Civil Code. The memoranda include express references to healers, chiropractitioners, etc., in terms of health care. Government resolutions are legally binding for all ministries. Therefore, the Ministry of Health, too, must abide by them. As for the Czech law, the status of natural healers is basically satisfactory.

Although there is no specific legal regulation in the Czech Republic, the status of natural healers is regulated by general legal provisions which are quite strict. Since 1991, healing has continuously been a free trade which follows the Act on Private Enterprise of May 1990. With effect from 2001, this trade has been on the Government-created open list of "services of personal nature" without being explicitly mentioned. An exception from the Trade Act in favor of the content framework of a special law, already anticipated in 1991, cannot be applied. No such law has ever been adopted. What still applies is then the Trade Act, subject to general assumptions of trades. They are not considered to be health services. Deceptive practices and other improprieties are prohibited.

The legal basis is in the private-law status of an expert and proper care of an expert, in accordance with the rules of their profession, for example herbalism. Keeping records of health care is provided for by the 2012 Civil Code coming 
into effect in 2014. Protection of personal data is also prescribed by law. The harmed customers have the option of out-of-court settlement of consumer disputes besides the right to go to court. Supervision is carried out by trade authorities and the Czech Trade Inspection which is also authorized to deal with out-ofcourt settlement of consumer disputes. The criminal-law status and the tax status of natural healers are also satisfactory. Both private and criminal liabilities are very strict. It also covers negligence. In addition, there is an offense in the field of health care which covers providing of health services to patients. We can also use the findings of the German case law, among others, in matters of professional care. Healing has been a common profession for years in Germany. Occasional media statements about legal irresponsibility of healers or about the fact that there is no regulation of keeping records for them can be ignored.

There is an economic problem that on the Czech market one cannot arrange professional liability insurance for such cases. Thus the situation on the insurance market is of no good for anyone.

A hotly debated issue is a professional examination, if desired, as it is probably the case with herbalism. It would be governed by the Act on recognition of further education, which is a matter for the Ministry of Education, Youth and Sports. The difficulty, however, lies in the fact that natural healing is varied. The so-called true healing means influencing health through alleged special personal abilities. These abilities tend to be tied to qualitatively variable phenomena, such as the sensibility of the healer and sometimes even the spiritual state or the mood of the sick person. Similarly, in health services, there is the patient's ability to be hypnotized in clinical hypnosis. So qualitative variables of this type may impede a uniform objectifying practical examination of professionals as they are tied to certain internal conditions on both sides, also associated with confidence. People with the gift of true healing are few as, for example there are few violin virtuosos.

The healer tends to be an "artist" of a certain kind. Helpfulness and insight into the situation of the disabled person and his current mood play their role, too. Inspiration cannot be ruled out, either. Intuition is actually known from other fields such as inventing. We may see something like this in some medical doctors, too.

The government's intention to include natural medicine in the health care system was abandoned years ago, and it was right. The regulation-tied health care system would then include a part of religious freedom which would cease to be a constitutionally guaranteed freedom.

\section{Healing and religion}

The legislative efforts to legally regulate natural medicine on the market must be constitutionally prudent. For some people healing can be a world view or a part of it. For others, in turn, it is freedom of religion and belief. Indeed, 
in the Czech Republic, there is a so-called healing church, the Community of Josef Zezulka, a religious society associated with biotronics. Anthroposophical medicine, in turn, ranked among the traditional European medicine, is associated with the Christian Community in the Czech Republic. Healing issues are also associated with the Religious Society of Czech Unitarians. Similarly, we could say that about four Czech religious corporations with the foundations of faith based on Eastern thought, e.g., in connection with the Indian Ayurveda. In contrast, the Roman Catholic Church tends to be prudent, or even dismissive, in issues of healing connected with spirituality. This church has a similar attitude to specific homeopathic products with therapeutic indications according to the drug law, even those of them that are sold only on prescription with regard to the drug law. On the other hand, it is this church, partially opposing the drug law, which practices exorcism of evil spirits. But it does so according to its conception which it considers to be spiritually, and perhaps also physically, safe.

The large Christian churches, widely present in this country, recognize the anointing of the sick. In the Orthodox Church it is called the Secret of anointing the sick. Its purpose is to strengthen the spirit of a sick man in an attempt to recover his health.

Many famous healers of the recent time were strongly religious people, e.g. Jindřich Paseka, who has a plaque dedicated by the village of Svratouch, Božena Kamenická having a plaque in Radnice, or Father František Ferda who has a commemorative plaque dedicated by the towns of Sušice and Spálené Poříčí. Thankful people, grateful towns.

Naturel medicine and religion have something in common. Both of them philosophically assume an effect of a subtle-material or even spiritual power regardless of the current possibility of its biophysical quantification. Indeed, it is not possible to quantify biophysically the strength of a doctor's captivating effect on the patient in a clinical hypnosis, either. Likewise, one cannot quantify the power of a bibliotherapeutic influence of a clinical psychologist within the health care services provided on the market, or the hagiotherapy power in pastoral medicine. There are a number of other examples.

\section{The right to pursue one's own happiness}

According to the Civil Code everyone can pursue one’s happiness ( $\$ 3$, Para 1). Private autonomy of every human being in private-law circumstances is expressed in this manner. Each of us can seek his/her fortune in different places, and see it in something different. This includes one's own health care or other personal values. It is essential that the state says "one's own" happiness, which means "one's own" health, too. Nevertheless, there is a limit established by the Civil Code. No one is allowed to cause harm by doing so. 
Freedom to choose one's own health care is an independent, responsible decision of each individual. In some cases, being informed is a precondition. Freedom can be applied by self-medication, home therapy, or with the help of another person. The question of public health insurance is quite a different issue, albeit an important one. In some circumstances, home health care within the family or self-medication may be sufficient, safe and effective, particularly in the case of less serious illnesses. It also tends to be better for public health insurance funds. It is just enough to consider the possible benefit of a loving home environment and its favorable impact on the soul of the patient.

If, for example, in some families a malady is traditionally treated with a certain wrap the efficacy and safety of which are commonly observable even by lay persons, such a treatment cannot be constitutionally criticized, unless that causes somebody harm. The composition of the wrap and the whole process can be a matter of family or local traditions orally transmitted from generation to generation. In addition to the conventional scientific medicine, there is still "old wives' advice". It would be unwise and also unconstitutional to prevent a family from spreading the information about their way of treatment among other families or in the public, even if it were for a reward or another benefit.

\section{Prohibition for the State to be bound by an exclusive ideology or religion}

The Czech state is based on civic society and rule of law. It is a secular state which is designed to protect the rights of free people and to organize public affairs in the interest of public welfare. Therefore, since 1991, the Constitution has banned the State to be bound by an exclusive ideology or religion (Art. 2, Para 1, the Charter of Fundamental Rights and Freedoms). That prohibition is among the defining features of the Czech state and has far-reaching effects for the free public life and the exercise of fundamental rights.

Thus, in ideological or religious terms, there is no "only right" way for the State. On the contrary, a free public space remains open for the clashing of ideas. Neither is the State allowed to be bound exclusively by the scientific world view in any form, as it would constitute a prohibited action. On the other hand, it does not mean at all that the State cannot, to some extent, regulate the market in order to protect the weaker parties, customers or patients. Nevertheless, the State does not stipulate whether we have to take care of our health only according to the rules of science, or otherwise. The State allows, in addition to the offers of the modern Western scientific medicine, a free space for traditional medicine, including natural healing, or exotic medicine, not to mention the spiritual care. The state protection of the weaker customer party does not mean a ban on certain activities on the open market of services. 
In the European context, we may come across the defense of spiritual human rights through the Soteria International, based in Denmark. ${ }^{9}$ In the Czech political environment there exists the Key Movement having a legal form of political movement, and in 2013 having a candidate for President of the Republic. ${ }^{10}$ The movement is based on the social dimension of anthroposophical thought. Its political program aims at giving the natural and alternative medicine the same rights as the allopathic medicine has. ${ }^{11}$

The fact is that sometimes there are philosophical conflicts among people, for example, clashes of supporters of scientific naturalism and atheism and followers of other beliefs, worldviews or religions. But it is not the role of the State to decide ideological disputes that arise from different natures of people or economic or power interests. Neither the State should regulate things between "Heaven and Earth". Just recall the various "miraculous healing” which, scientifically speaking, should not have occurred at all and he patient should have already been dead. The State's role, on the contrary, is to protect tolerability as the public good. This role must be applied by each organizational unit of the State according to their position and within their power.

The human cognitive tools include not only reason but also emotions. Philosophically speaking, this is the dichotomy "Reason" and "Heart". "Open up!", "But for whom? Where?, "For your heart! Yes, there!", says in his Parzival Wolfram von Eschenbach.

The 2012 Civil Code establishes knowability of natural rights associated with human being, i.e. with health, reason and emotions, too. Just recall the aesthetic perception of fine art and we come to the knowability of the existence of natural copyright of a person, recognized by the law and protected by the court. Similarly, as we perceive the beauty of art and the beauty of nature, so, sometimes, at least some of us perceive maladies of a spirit, a soul and a body. Or conversely, the beauty of a spirit, a soul and a body.

The relationship between spiritual care or healing and scientific medicine could be like the that one between music and musical science. As the delighted music listeners is not interested in the sound frequency of the orchestra, so the healed and happy, patient is not interested in the scientific-technical data of his recovery process.

Anyone can express freely and responsibly their "own" selves. It does not mean, however, that we are allowed to belittle or condemn our professional colleagues, or, as it used to be the case in the Middle Ages, even burn them.

9 http://www.soteriainternational.org/, [Accessed 2. 5. 2016].

10 The candidate was its chairwoman Fischerová.

11 http://www.klicovehnuti.cz/cs/program, [Accessed 2. 5. 2016]. 
ICLR, 2017, Vol. 17, No. 2.

A few words at the end: "The interests and welfare of the human beings are superior to the interests of society and science," says the Convention on Human Rights and Biomedicine of 1997 which was ratified and made effective by the Czech Republic in 2001.

\section{References}

ILLICH, I.: Limity medicíny. Nemesis medicíny - zaprodané zdraví. (Limits to Medicine. Nemesis of Medicine, the Expropriation of Health). Brno, Emitos 2012.

KOMÁREK, S.: Tělo, duše a jejich spasení aneb Kapitoly of moci, nemoci a psychosomatice (The body, soul and salvation, or Chapters of power, illness and psychosomatics). Praha, Academia 2015. 